\title{
Prediction of Cohesive Sediment Transport and Flow Resistance Around Artificial Structures of the Beolgyo Stream Estuary
}

\author{
Young Jun Cho ${ }^{1}$, Sung Su Hwang ${ }^{2}$, Il Heum Park ${ }^{1 *}$, Yo Han Choi ${ }^{1}$, Sang-Ho Lee ${ }^{3}$, \\ Yeon-Gyu Lee ${ }^{1}$, Jong-Gyu Kim ${ }^{1}$ and Hyun Chool Shin ${ }^{1}$ \\ ${ }^{1}$ School of Marine Technology, Chonnam National University, Yeosu 550-749, Korea \\ ${ }^{2}$ Institute of Geometics, Saehan Aero Survey Co. Ltd., Seoul 150-972, Korea \\ ${ }^{3}$ School of Construction Engineering, Pukyong National University, Busan 608-737, Korea
}

\begin{abstract}
To predict changes in the marine environment of the Beolgyo Stream Estuary in Jeonnam Province, South Korea, where cohesive tidal flats cover a broad area and a large bridge is under construction, this study conducted numerical simulations involving tidal flow and cohesive sediment transport. A wetting and drying (WAD) technique for tidal flats from the Princeton Ocean Model (POM) was applied to a large-scale-grid hydrodynamic module capable of evaluating the flow resistance of structures. Derivation of the eddy viscosity coefficient for wakes created by structures was accomplished through the explicit use of shear velocity and Chezy's average velocity. Furthermore, various field observations, including of tide, tidal flow, suspended sediment concentrations, bottom sediments, and water depth, were performed to verify the model and obtain input data for it. In particular, geologic parameters related to the evaluation of settling velocity and critical shear stresses for erosion and deposition were observed, and numerical tests for the representation of suspended sediment concentrations were performed to determine proper values for the empirical coefficients in the sediment transport module. According to the simulation results, the velocity variation was particularly prominent around the piers in the tidal channel. Erosion occurred mainly along the tidal channels near the piers, where bridge structures reduced the flow cross section, creating strong flow. In contrast, in the rear area of the structure, where the flow was relatively weak due to the formation of eddies, deposition and moderated erosion were predicted. In estuaries and coastal waters, changes in the flow environment caused by artificial structures can produce changes in the sedimentary environment, which in turn can affect the local marine ecosystem. The numerical model proposed in this study will enable systematic prediction of changes to flow and sedimentary environments caused by the construction of artificial structures.
\end{abstract}

Key words: Beolgyo Stream Estuary, Cohesive sediment transport, Erosion and deposition, Flow resistance of structures, Numerical simulation, Tide and tidal flow

\section{Introduction}

Tidal flats are particularly well-developed along the southern coast of South Korea, incorporating finegrained cohesive sediments (Choi, 2004). Such sediments adsorb various pollutants entering coastal waters and are transported with the water. Surface sediments are eroded by the strong shear stress of tidal flows, generating high concentrations of suspended sediment that can have severe impacts on

*Corresponding author: parkih@chonnam.ac.kr water quality in coastal waters. Meanwhile, the erosion of bottom sediments leads to increased water depths in places with strong flow, while the suspended load is deposited in weak flow regions, decreasing the water depth. Furthermore, the highly concentrated suspended solids produced by cohesive sediments deteriorate water quality and can even destroy coastal ecosystems. In addition, sludge deposited at the bottom discharges nutrients and uses up oxygen in the water. This leads to problems such as eutrophication and an oxygen-deficient water mass, which in turn can contribute to algal blooms, some- 
times referred to as red tides. To resolve these problems, we must understand the sediment transport process and be able to predict the flow phenomena that transport such sediments (Jung et al., 2006; Mehta et al., 1989).

The Beolgyo Stream Estuary, located in the northwest part of Yeoja Bay, Jeonnam Province, has rich tidal flats with high biological productivity supported by an abundant supply of stream-transported organic matter. However, a bridge connecting Beolgyo Town with Goheung County is being constructed and the resulting changes to flow and sedimentation environments are expected to impact the marine ecosystem. In particular, bridge piers submerged in the water create flow resistance and, in turn, sudden flow variation. Such phenomena are generally difficult to compute, even when using finegrid hydrodynamic models such as large eddy simulation (LED) or direct numerical simulation (DNS) models, because these models simulate only a narrow area around the structure with high computational cost. While most large-scale-grid hydrodynamic models can simulate a wide area at low cost, the cross section of a bridge is considerably smaller than the size of the computational grid. Furthermore, it is difficult to evaluate the eddy viscosity around structures (Park et al., 1998).

In estuaries and coastal waters, cohesive sediment transport is associated with processes of erosiondeposition, advection-diffusion, and flocculation and consolidation, which are greatly influenced by the flow intensity, the physical nature of the fluids, and the physicochemical characteristics of cohesive sediments. Consequently, relatively few studies have examined cohesive sediment transport, in contrast to the numerous available studies on non-cohesive sediment transport. Research on cohesive sediment transport began in the 1950s with Einstein's study on the effects of flocculation for sediment deposition. Most early studies relied on flume experiments in the laboratory. Notable studies on deposition include those of Krone (1963), Mehta and Partheniades (1973), and Partheniades (1977), while notable erosion studies include those of Owen (1976), Partheniades (1965), Teeter and Pankow (1989), and Winterwerp et al. (1991). Starting in the 1980s, numerical simulations based on previous experimental results were actively undertaken by Mehta and Parchure (1982), Parchure (1984), Mehta et al. (1989), Gailani et al. (1991), Ziegler and Nisbet (1994), Shrestha and Orlob (1996), and Shrestha et al. (2000). However, further research is needed to determine the optimal values of critical shear stress relative to sediment characteristics, as the critical bed shear stress varies with the grain size, roughness, shape, density, and composition of sediments (van Rijn, 1984).

To predict change in the marine environment of the Beolgyo Stream Estuary, where cohesive tidal flats cov-er a broad area and a large bridge is being constructed, this study conducted numerical simulations involving tidal flow and cohesive sediment transport. A wetting and drying (WAD) technique for tidal flats from the Princeton Ocean Model (POM) (Oey, 2006) was applied to a large-scale-grid hydrodynamic module capable of evaluating the flow resistance of structures (Park, 2004; Park et al., 1998; Lee and Park, 1995). Derivation of the eddy viscosity coefficient for wakes created by structures was accomplished through the explicit use of shear velocity and Chezy's average velocity, with assumptions of uniform flow and a mild bottom slope. Furthermore, various field observations, such as those of tide, tidal flow, suspended sediment concentrations, bottom sediments, and water depth, were performed for verification and to obtain input data for the numerical model. In particular, geologic parameters related to the evaluation of settling velocity and critical shear stresses for erosion and deposition were observed, and numerical tests for suspended sediment concentrations were performed to determine proper values for the empirical coefficients in the sediment transport module. According to the above verifications, the tidal flow change and yearly bathymetric change reflecting the flow discharge and sediment load from Beolgyo Stream are discussed.

\section{Materials and Methods}

\section{Study Area}

The Beolgyo Stream Estuary, located in the northwestern part of Yeoja Bay along South Korea's south-central coast, is characterized by well-developed tidal flats (Fig. 1). The area is renowned for high productivity supported by the rich organic matter carried there by inland streams (Choi, 2004). Because of its high biological productivity, this region has long been actively exploited by coastal and village fisheries. However, environmental changes resulting from a new bridge construction linking Beolgyo Town and Goheung County are expected to have a significant impact on the local marine ecosystem.

\section{Hydrological Characteristics of Beolgyo Stream}

The drainage basin of Beolgyo Stream includes 


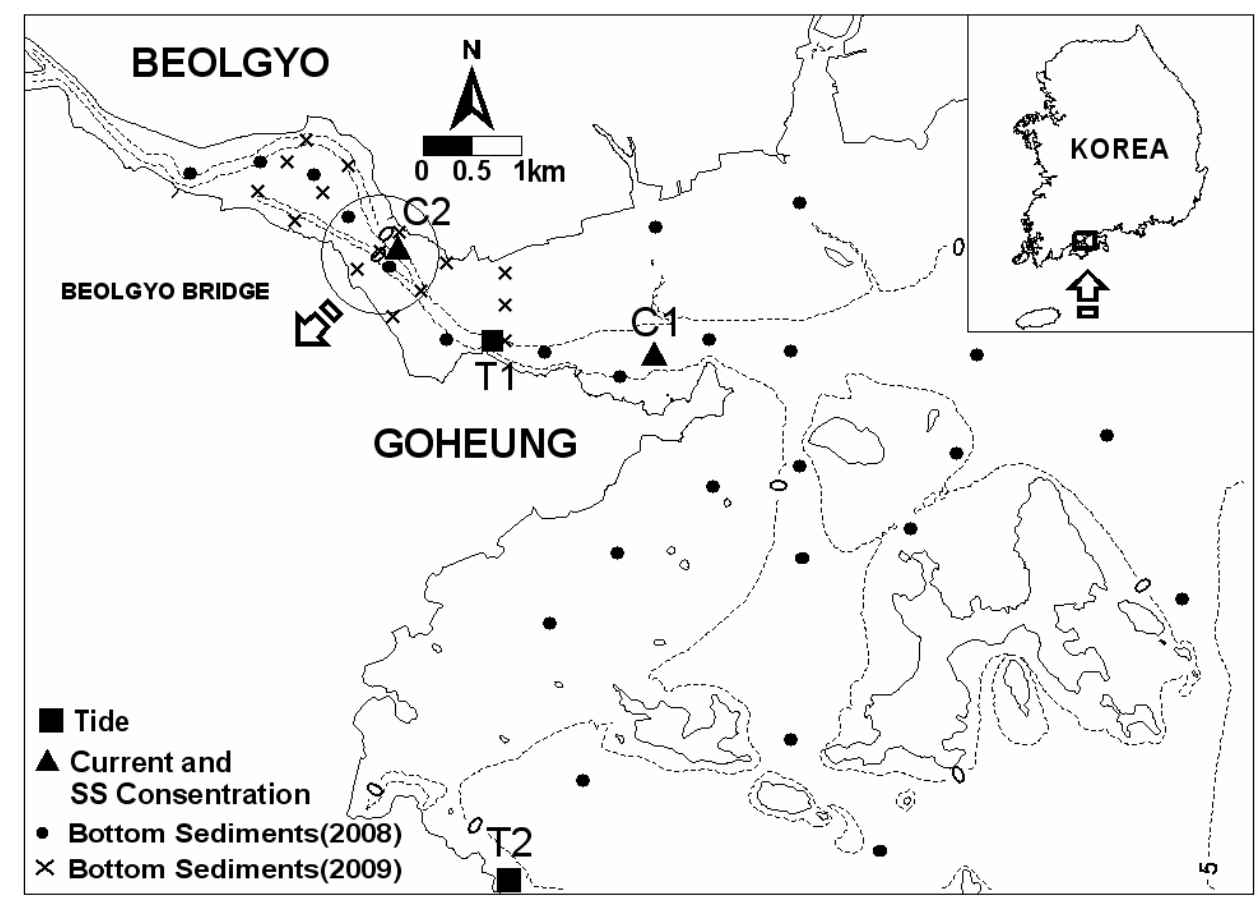

Fig. 1. Sampling stations and topography of the study area (dotted lines are the water depth from the ALLWL).

two branch streams, Childong Stream and Yangchon Stream, and covers parts of both Beolgyo Town in Boseong County and Nakan Subcounty of Suncheon City in Jeonnam Province. The basin area is characterized by small- to medium-scale streams over an area of $116.4 \mathrm{~km}^{2}$. The main stream, Beolgyo Stream, starts at Chudong Village of Beolgyo Town and flows approximately $8 \mathrm{~km}$ southeast before joining Nakan Stream flowing from the north. Beolgyo Stream later joins Childong Stream in the west and Yangchon Stream in the north, before finally reaching the estuary. The Beolgyo Stream Estuary is strongly affected by tide and tidal flow as it is connected with vast Yeoja Bay that links to the southern Sea of Korea. Based on weather data for the past 35 years (19732008), a continuous simulation of river discharge for Beolgyo Stream using the Storm Water Management Model (SWMM; Huber and Dickinson, 1988) yielded a normal season flow rate $\left(3.743 \mathrm{~m}^{3} / \mathrm{s}\right)$ with a normal sediment concentration $(242.8 \mathrm{mg} / \mathrm{L})$, and a summer season (Jul.-Sep.) flow rate $\left(27.228 \mathrm{~m}^{3} / \mathrm{s}\right)$ with a summer season sediment concentration $(499.6 \mathrm{mg} / \mathrm{L})$. Notably, the maximum flow rate, which was recorded in 2002 during Typhoon Rusa, was calculated to be $887.67 \mathrm{~m}^{3} / \mathrm{s}$ with a sediment concentration of $1,152.5$ $\mathrm{mg} / \mathrm{L}$.

\section{Field Observations}

Tide was observed at two stations, T1 and T2, while tidal flow was observed at two other stations, $\mathrm{C} 1$ and $\mathrm{C} 2$ (Fig. 1). The tide was observed at 30 minute intervals during one month (Aug. 2008) using a tide gauge (TWR-2050, RBR Ltd., Canada). The tidal flow was measured during 25 hours of spring tide (3 Aug. 2008) and neap tide (10 Aug. 2008) using a Doppler-type current meter (RCM-9, Aanderaa, Ltd., Norway) at 10 minute intervals. During the same period as the tidal flow observations, the continuous suspended sediment concentration was observed at the same stations $(\mathrm{C} 1$ and $\mathrm{C} 2)$. The concentrations were then obtained in the middle and surface layers with 1-hour intervals using a Vandon-type water sampler. On 3 Aug. 2008 (spring tide) and 10 Aug. 2008 (neap tide), the spatial distribution of suspended sediment concentrations was observed at 28 stations (• symbols in Fig. 1). The above observed data were used for verification and input data for the numerical simulations.

In Jul. 2008, surface sediments were collected from a grab-type sampler at 28 stations (• symbols in Fig. 1) and the grain size and composition of the sediments were analyzed. The results showed that this area is dominated by cohesive grains including finegrained clay with a mean grain size of 8.23 ø. To determine the critical shear stresses for erosion and deposition in the area, surface sediments from 15 stations (x symbols in Fig. 1) were collected in May 2009, and each sediment sample was analyzed for 
organic content, sand content, and dry density in the laboratory. The analyzed results were used as reference values in the erosion and deposition formula.

No official bathymetric survey exists for the Beolgyo Stream Estuary intertidal region. The lack of survey data posed additional challenges to numerical experimentation. To obtain water depth data, a bathymetric survey was conducted mainly around the upstream area and tidal flats, where no official charts were available. Field work was conducted from 1 Aug. to 12 Sep. 2008. At high water, depth data were acquired using a precision echo-sounder (E-Sea Sounder 103, Odom Hydrographic System Inc., USA); at low water when use of a boat was impractical, a staff survey was conducted. Horizontal positioning data were obtained using a DSM-232 DGPS receiver (Trimble Navigation Ltd., USA). To determine the mean sea level (MSL) and approximate lowest low water level (ALLWL), tidal data obtained during the same period were used. To calibrate the sound speed of the echo-sounder, bar checks were performed before and after the surveys. The depth contours shown in Fig. 1 reflect the results of this bathymetric survey.

\section{Numerical Model of Tidal Flow and Cohesive Sediment Transport}

The numerical model used in this study was a modified code of the Depth-Integrated Velocity and Solute Transport (DIVAST) model originally developed by Falconer (1976) and improved by Falconer (1991) and Falconer and Owens (1987). To apply the flow resistance of bodies, a module of the drag force term was included in the DIVAST code (Park, 2004; Park et al., 1998; Lee and Park, 1995). The governing equations used in the model to determine the water elevation and velocity fields were based on integrating the three-dimensional Navier-Stokes and continuity equations over the water depth. Assuming a hydrostatic pressure distribution and the Boussinesq approximation, the continuity and $\mathrm{x}$ and $\mathrm{y}$ direction momentum equations can be respectively given as follows:

$$
\begin{aligned}
& \frac{\partial \zeta}{\partial t}+\frac{\partial q_{x}}{\partial x}+\frac{\partial q_{y}}{\partial y}=0 \\
& \frac{\partial q_{x}}{\partial t}+\beta\left(\frac{\partial U q_{x}}{\partial x}+\frac{\partial V q_{x}}{\partial y}\right)=f q_{y}-g H \frac{\partial \zeta}{\partial x}+\frac{1}{\rho} \int_{-h}^{\zeta} \frac{\partial \tau_{x}}{\partial z} d z+ \\
& 2 \frac{\partial}{\partial x}\left(\varepsilon H \frac{\partial U}{\partial x}\right)+\frac{\partial}{\partial y}\left\{\varepsilon H\left(\frac{\partial U}{\partial y}+\frac{\partial V}{\partial x}\right)\right\}
\end{aligned}
$$

$$
\begin{aligned}
& \frac{\partial q_{y}}{\partial t}+\beta\left(\frac{\partial U q_{y}}{\partial x}+\frac{\partial V q_{y}}{\partial y}\right)=-f q_{x}-g H \frac{\partial \zeta}{\partial y}+\frac{1}{\rho} \int_{-h}^{\varsigma} \frac{\partial \tau_{y}}{\partial z} d z+ \\
& 2 \frac{\partial}{\partial y}\left(\varepsilon H \frac{\partial V}{\partial y}\right)+\frac{\partial}{\partial x}\left\{\varepsilon H\left(\frac{\partial U}{\partial y}+\frac{\partial V}{\partial x}\right)\right\}
\end{aligned}
$$

where $\zeta=$ water surface elevation; $t=$ time; $q_{r}, q_{v}=$ depth-integrated velocity components in $\mathrm{x}$, y directions; $\beta=$ momentum correction factor for nonuniform vertical velocity profile; $U, V=$ depth averaged velocity components in $\mathrm{x}, \mathrm{y}$ directions; $f=$ Coriolis parameter; $g=$ gravitational acceleration; $H=$ total depth of the water column; $\rho=$ fluid density; $\tau_{r}$, $\tau_{v}=$ shear stress components in $\mathrm{x}, \mathrm{y}$ directions; and $\varepsilon=$ depth-averaged eddy viscosity.

The shear stress term for the $\mathrm{x}$ direction and $\mathrm{a}$ similar representation for the y direction considering the wind friction, bottom friction, and drag of resistance bodies can be written as Eq. (4). The first term on the right-hand side is the wind stress for the steady-uniform flow, the second term is bed shear stress for the second-order frictional law of steadyuniform flow in an open channel, and the third term is the drag stress of resistance bodies (Park, 2004; Park et al., 1998; Lee and Park, 1995):

$$
\begin{aligned}
\frac{1}{\rho} \int_{-h}^{\varsigma} \frac{\partial \tau_{x}}{\partial z} d z= & \frac{\gamma \rho_{a} W_{x} W_{s}}{\rho}-\frac{g U \sqrt{U^{2}+V^{2}}}{C^{2}} \\
& \frac{n C_{D x} A_{D x} U_{a} \sqrt{U_{a}^{2}+V_{a}^{2}}}{2}
\end{aligned}
$$

where $\rho_{a}=$ air density; $\gamma=$ air-water resistance coefficient; $W_{r}, W_{v}=$ wind velocity component in $\mathrm{x}, \mathrm{y}$ directions; $W_{s}=$ wind speed; $C=$ Chezy coefficient; $n=$ number of resistance bodies per unit area; $C_{D x}$, $C_{D y}=$ drag coefficient in $\mathrm{x}, \mathrm{y}$ directions; $A_{D x}, A_{D y}=$ projection area of bodies in $\mathrm{x}, \mathrm{y}$ directions; $U_{a}, V_{a}=$ approaching velocity in $\mathrm{x}, \mathrm{y}$ directions; and $n=$ number of resistance bodies in unit area. When the present numerical model is run in the real grid system, $U_{a}$ and $V_{a}$ can be used as the one grid upstream value in front of bodies.

On the other hand, WAD is a common and important phenomenon along the southern and western coasts of South Korea, where a high tidal range affects vast tidal flats. A number of WAD schemes have been implemented in coastal models. In this study, a WAD technique that was applied to the POM (Oey, 2006) was introduced to the present model. The scheme defined dry cells as regions with a thin film of fluid. The governing equations were solved in the thin films as well as in other regular wet cells. The scheme required only flux-blocking conditions across 
cells' interfaces when wet cells became dry, while dry cells were temporarily dormant and dynamically activated through mass and momentum conservation. Namely, bathymetric depth $H$ is the non-negative and vertical distance from the datum to the bottom topography: $H=H_{M S L}+H_{H I}$, where $H_{H I}$ is always a positive constant height of the datum from the MSL and $H_{M S L}$ is the height from the bottom to MSL. Thus land is where $H_{M S L}=-H_{H I}$ or $H=0$. Then, the water surface measure from the datum is $\zeta(x, y, t)=\zeta_{M S L}(x, y, t)$ $-H_{H L} \leq 0$, where $\zeta_{M S L}(x, y, t)$ defines deviation of surface elevation from the MSL. The total water depth is then

$$
D=H+\zeta(x, y, t)=H_{M S L}+\zeta_{M S L}(x, y, t)
$$

The second expression for $D$ in Eq. (5) is the same as the usual definition for other models. By the above definition, the WAD treatment logic is clear because the bathymetric depth is always positive and the water elevation is always negative or zero both in wet cells of the ocean area and in iterative wet-dry cells of the tidal flat area. Therefore, a blocking condition for flux at cell interfaces can be easily applied.

Most sediment transport formulations of suspended sediment flux are based on the numerical solution of the depth-integrated advection-diffusion, given by Eq. (6) (Falconer, 1986):

$$
\begin{aligned}
& \frac{\partial S H}{\partial t}+\frac{\partial S U H}{\partial x}+\frac{\partial S V H}{\partial y}-\frac{\partial}{\partial x}\left(H D_{x x} \frac{\partial S}{\partial x}+H D_{x y} \frac{\partial S}{\partial y}\right) \\
& -\frac{\partial}{\partial y}\left(H D_{y x} \frac{\partial S}{\partial x}+H D_{y y} \frac{\partial S}{\partial y}\right)=E
\end{aligned}
$$

where $S=$ depth-averaged suspended sediment concentration; $D_{x x}, D_{x y}, D_{y x}, D_{y y}=$ depth-averaged longitudinal dispersion and turbulent diffusion coefficients in $\mathrm{x}, \mathrm{y}$ directions; and $E=$ net erosion or deposition per unit area of the bed.

In the modeling of cohesive sediment transport, the particles have cohesive properties due to electrostatic forces comparable to the gravity forces active between the particles (van Rijn, 1984). Therefore, the term $E$ is written as

$$
E=\frac{d m_{S}}{d t}
$$

where $m s=$ mass of sediment per unit area. The term given in Eq. (7) is used to define the erosion or deposition according to the following criteria:

$$
\text { Deposition }: \frac{d m_{S}}{d t}=W_{f} S\left(\frac{\tau_{b}}{\tau_{d}}-1\right) \text { when } \tau_{b} \leq \tau_{d}
$$

$$
\begin{array}{ll}
\text { Erosion: } \quad \frac{d m_{S}}{d t}=M\left(\frac{\tau_{b}}{\tau_{e}}-1\right) & \text { when } \tau_{b} \geq \tau_{e} \\
\text { Neither : } \quad \frac{d m_{S}}{d t}=0 & \text { when } \tau_{d}<\tau_{b}<\tau_{e}
\end{array}
$$

where $W_{f}=$ particle settling velocity, $\tau_{b}=$ bed shear stress, $\tau_{d}=$ critical shear stress for deposition, $\tau_{e}=$ critical shear stress for erosion, and $M=$ empirical erosion constant (0.00001-0.0005). Most parameters included in the above formulations for Eq. (8) depend on local sediment characteristics. Typical values of critical shear stresses for erosion and deposition have been reported by van Rijn (1993) for a range of different mud types.

Settling velocity can be calculated using Stoke's Law with the individual particle size when the suspended sediment concentrations are very low. On the other hand, in suspensions with sediment concentrations up to approximately $1,000 \mathrm{mg} / \mathrm{L}$, an increase of the settling velocity with concentration has been observed as a result of the flocculation effect both in laboratory and field conditions. These effects are incorporated into the following two ranges of settling velocity:

$$
\begin{aligned}
& W_{f}=\frac{\left(\rho_{s} / \rho-1\right) g d^{2}}{18 v} \quad \text { when } S \leq 10 \mathrm{mg} / \mathrm{L} \\
& W_{f}=k S_{v}^{m} \quad \text { when } 10 \mathrm{mg} / \mathrm{L}<S<10,000 \mathrm{mg} / \mathrm{L}
\end{aligned}
$$

where $\rho_{s}=$ sediment density, $d=$ particle diameter, $v=$ kinetic viscosity, $S_{v}=$ volume concentration, and $k$ and $m=$ coefficients.

The above governing equations are solved using the finite difference method and a scheme based on the alternating direction implicit (ADI) formulation. The advective accelerations are written in a timecentered form for stability, with these terms and the turbulence diffusion terms being centered by iteration While the model has no stability constraints, there is a Courant number restriction for accuracy in the hydrodynamic module. The finite difference equations are formulated on a space-staggered grid scheme, with the water surface elevations and $\mathrm{x}$ direction velocity components being initially solved during the first half time step. The sediment flux distributions are then evaluated, before processing to the second half time step and repeating the process for the implicit description of the $y$ direction derivatives and velocity components. In the sediment transport modules, the advection terms are treated using a higher order accurate third-order upwind difference formulation; this scheme considerably 
reduces the introduction of artificial diffusion and under- and over-shoot in regions of high concentration gradients (Falconer, 1991).

\section{Results}

\section{Tide and Tidal Flow}

To verify the computed tide and tidal flow, the numerical solutions were compared with observed data. The numerical solutions for tide at stations T1 and T2 showed good agreement with the observed data in terms of phase and amplitude, as shown in Fig. 2. Fig. 3 shows the observed and simulated ellipses of tidal flow by the harmonic analysis. The semidiurnal flow was an east-west alternating flow with an amplitude of $0.4 \mathrm{~m} / \mathrm{s}$ at station $\mathrm{C} 1$ and a north-westsoutheast alternating flow with an amplitude of 0.6 $\mathrm{m} / \mathrm{s}$ at station $\mathrm{C} 2$, located near the bridge. These results demonstrate that the numerical results closely approximated the observed data.

As already emphasized, the area of interest has a broad tidal flat requiring reasonable treatment in numerical modeling. In this study, the POM WAD technique used by Oey (2006) was applied to the hydrodynamic module to resolve problems associated with the moving boundary of an intertidal region. To verify the WAD technique, the water depth (solid lines) at the ALLWL computed from the present model was compared with the survey data (dotted line), as shown in Fig. 4. Although the computed results showed some discontinuous contours in the tidal channel, the numerical solutions for the WAD scheme corresponded well overall with the surveyed data.

In Fig. 5, the pattern of flood and ebb flow in spring tide is shown with the condition of normal stream discharge based on the verified numerical model. Because of the topographical characteristics, the flood flow travels mainly in the north or northwest direction, while the ebb flow moves in the southeast or south direction. There were some regional differences, and the maximum speeds of flood and ebb flows were approximately $0.9 \mathrm{~m} / \mathrm{s}$ and $0.8 \mathrm{~m} / \mathrm{s}$, respectively.

\section{Cohesive Sediment Transport}

To verify the numerical module of cohesive sediment transport, observed and computed suspended sediment concentrations at stations $\mathrm{C} 1$ and $\mathrm{C} 2$ were compared, as shown in Fig. 6. The symbols $\circ$ and $\triangle$ represent the observed data and the solid lines are the computed solutions, which were determined

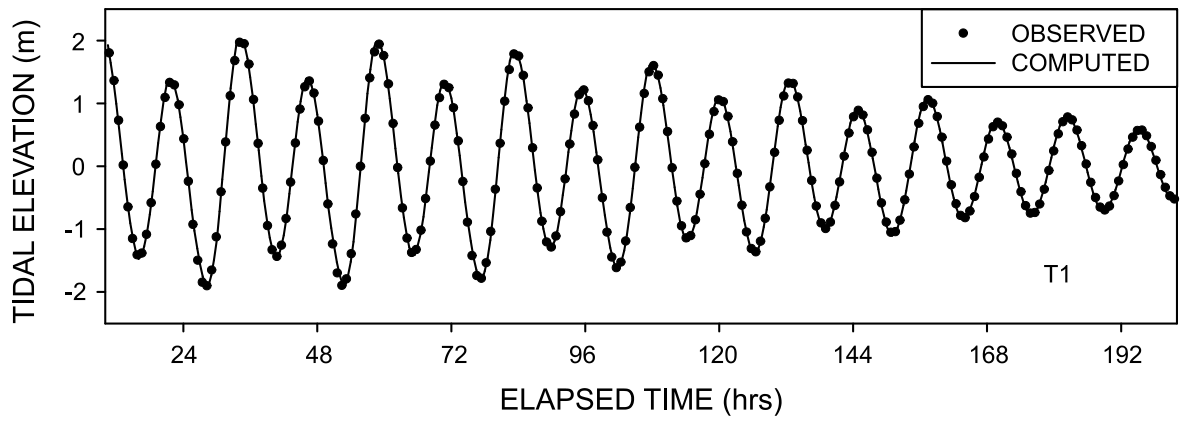

(a) Station T1

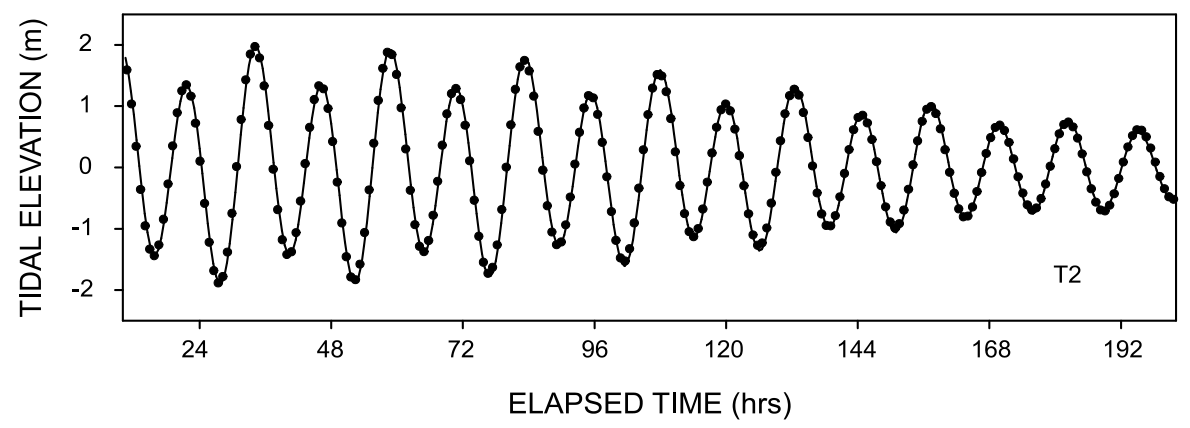

(b) Station T2

Fig. 2. Comparison of observed and computed tidal elevations in stations T1 and T2. 


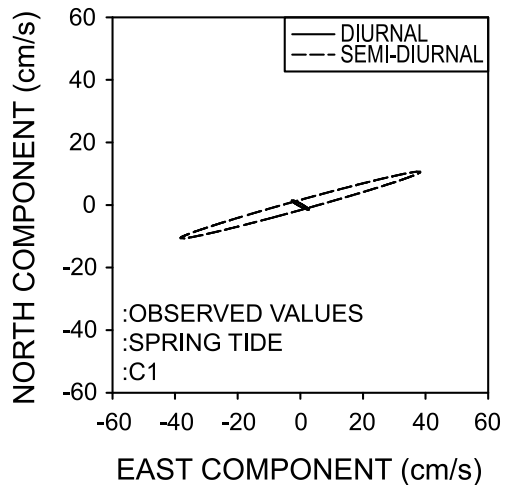

(a) Observed results in station $\mathrm{C} 1$

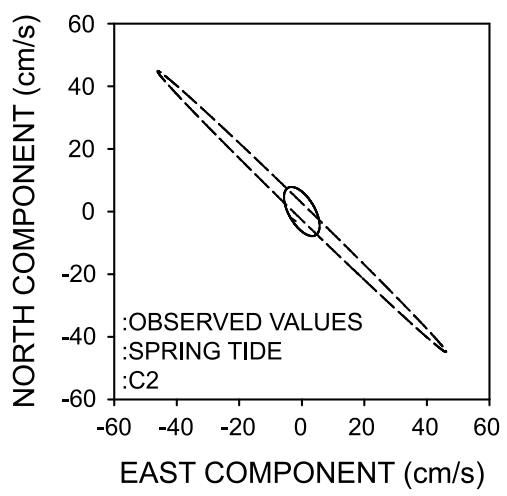

(c) Observed results in Station $\mathrm{C} 2$

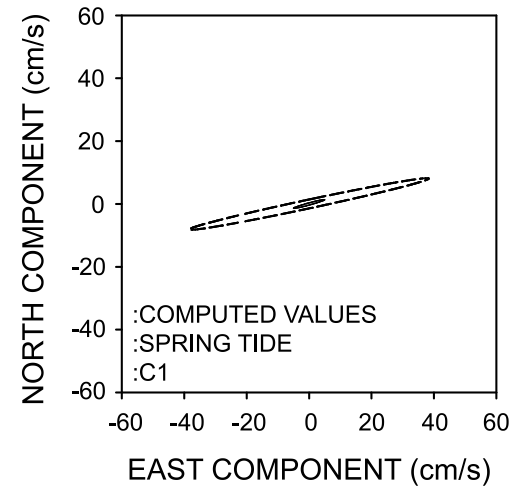

(b) Computed results in staton $\mathrm{C} 1$

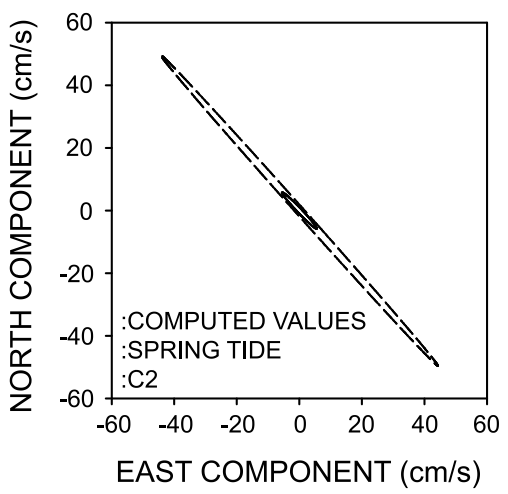

(d) Computed results in station $\mathrm{C} 2$

Fig. 3. Comparison of observed and computed tidal flow ellipses in stations $\mathrm{C} 1$ and $\mathrm{C} 2$.

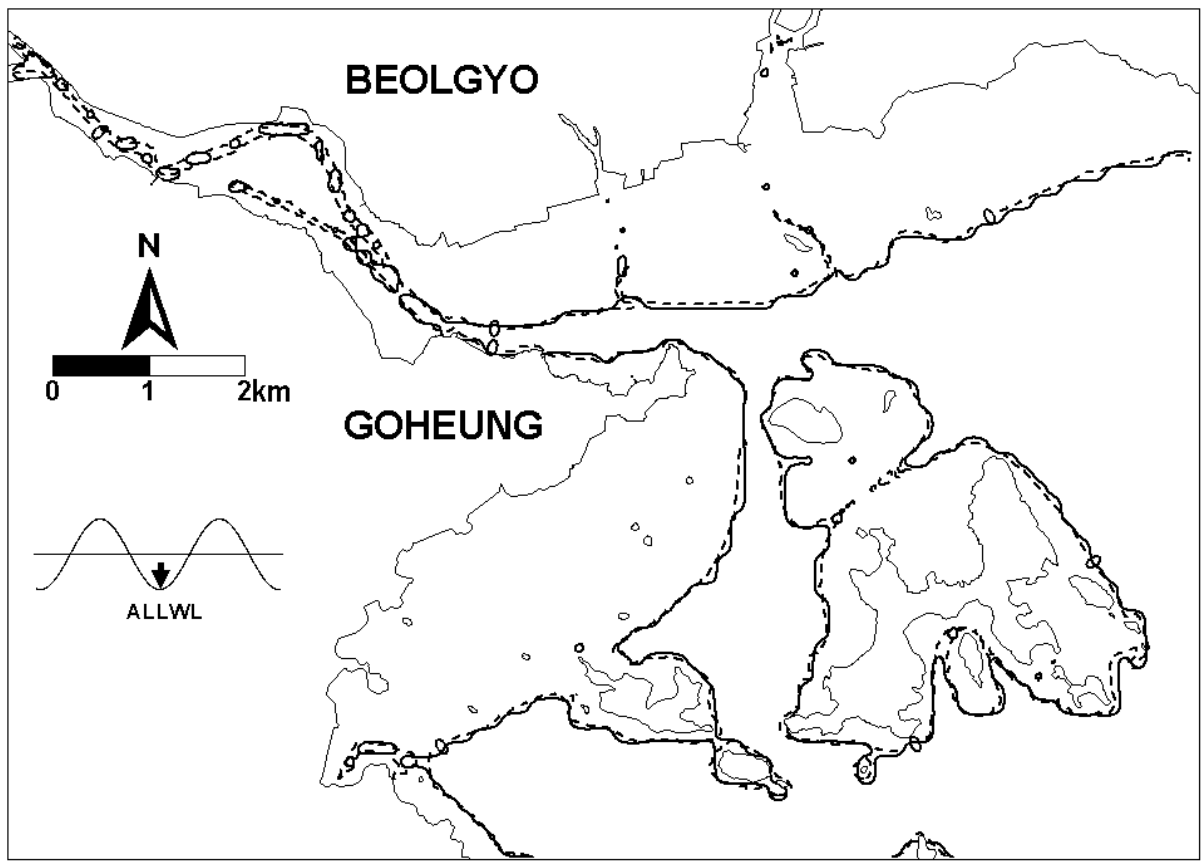

Fig. 4. Comparison of surveyed depth (dotted line) and computed depth (solid line) at ALLWL using the present WAD technique. 


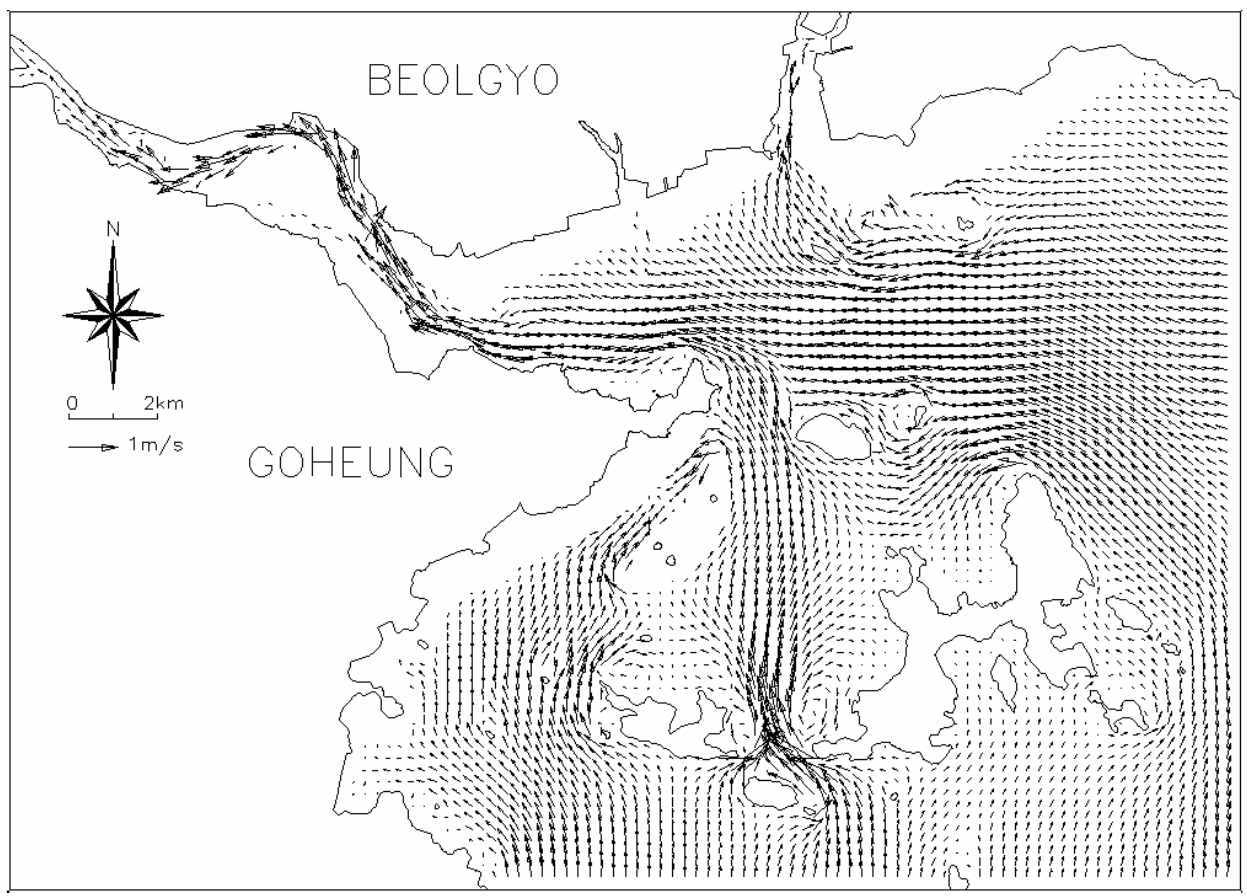

(a) Flood flow near mean water level

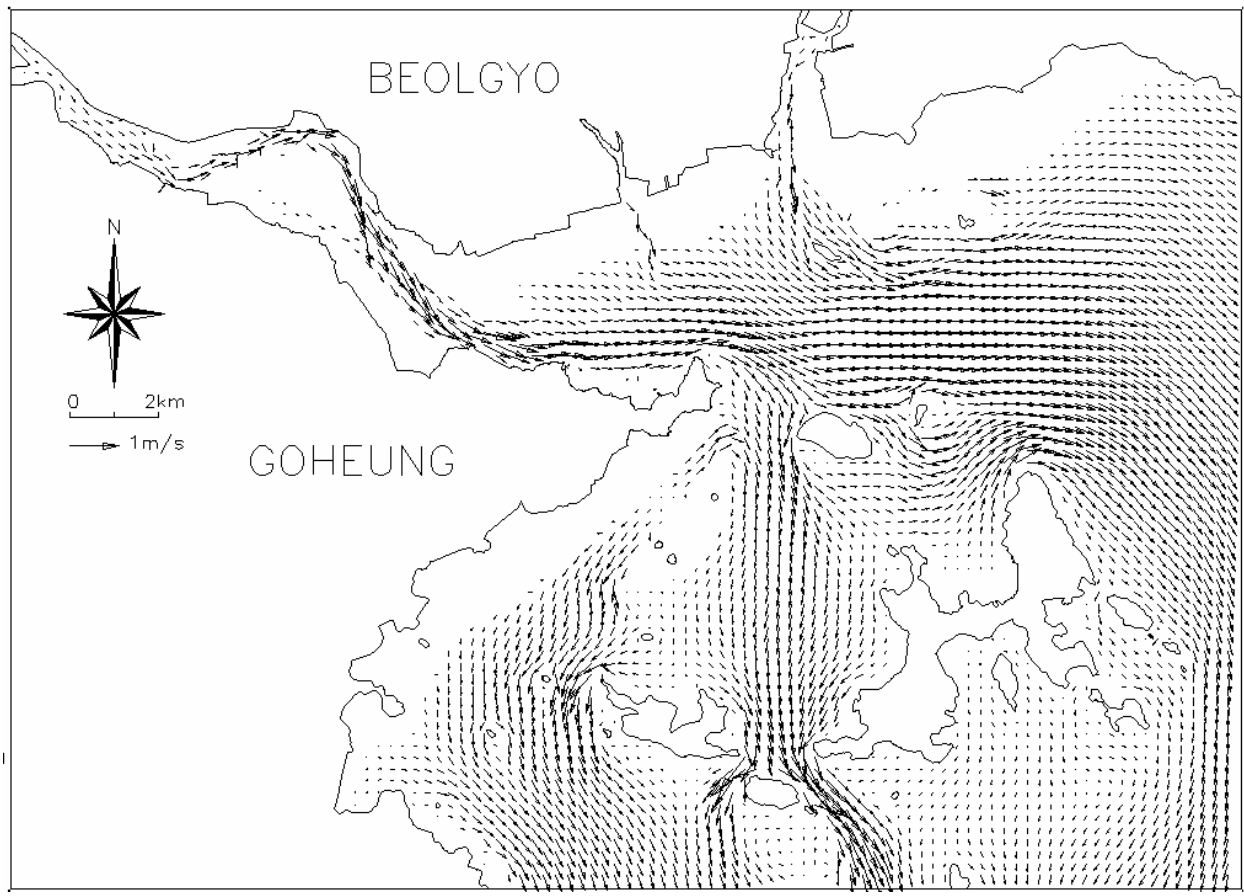

(b) Ebb flow near mean water level

Fig. 5. Predicted velocity field for a spring tide in Beolgyo Stream Estuary.

by trial and error with the observed geologic characteristics. The numerical solutions presented in Fig. 6 are results obtained after 150 hours of computation for a spring tide and a neap tide, respectively. That is, the results for spring (neap) tide started from an initial condition at neap (spring) tide with the observed background concentration.

The concentration of suspended sediment observed 

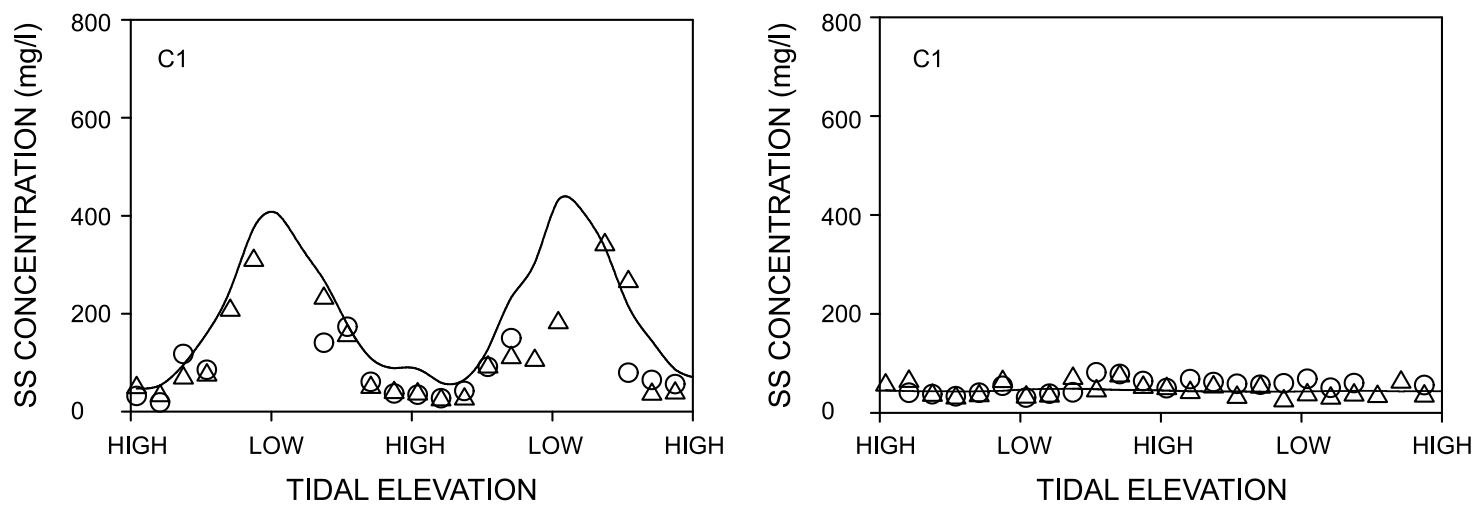

(a) Spring tide in station $\mathrm{C} 1$

(b) Neap tide in station $\mathrm{C} 1$

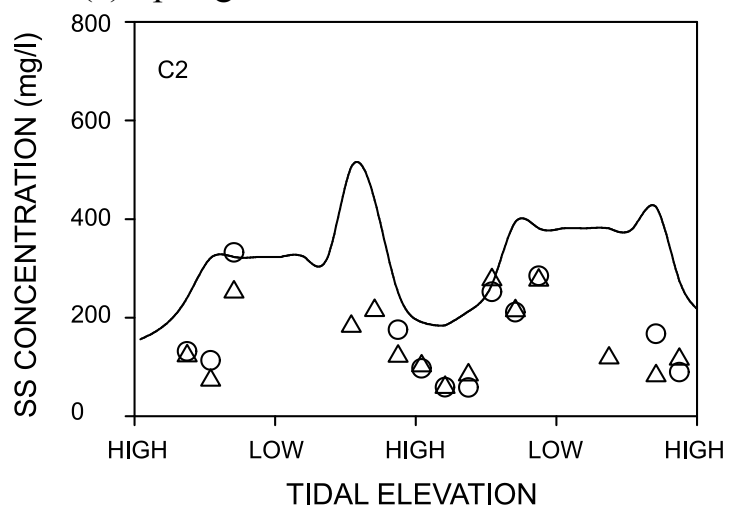

(c) Spring tide in station $\mathrm{C} 2$

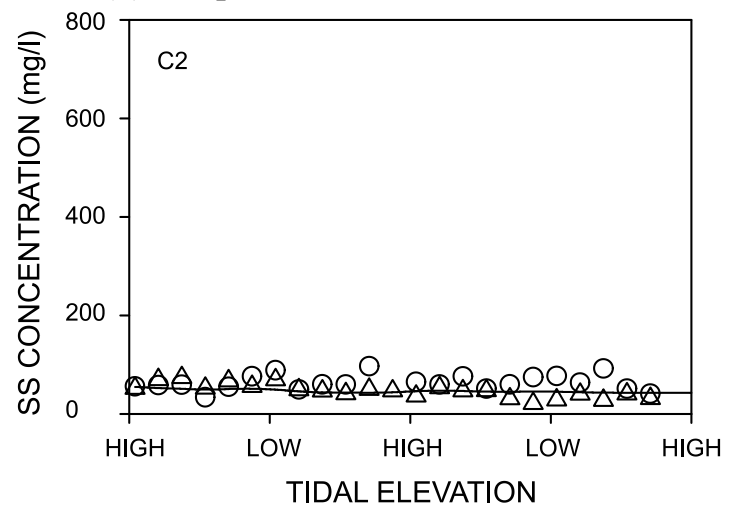

(d) Neap tide in station C2

Fig. 6. Comparison of observed and computed suspended sediment concentrations in stations $\mathrm{C} 1$ and $\mathrm{C} 2$ ( $\triangle$ and $\circ$ symbols are observed values and the solid line is computed values).

at station $\mathrm{C} 1$ for the spring tide varied from $20-380$ $\mathrm{mg} / \mathrm{L}$. The observed concentration gradually increased during ebb flow and reached its maximum at low water, whereas it decreased during flood flow and reached its minimum at high water. The computed values were nearly identical to the observed values within a range of $45-430 \mathrm{mg} / \mathrm{L}$ at station $\mathrm{C} 1$, as shown in Fig. 6(a). At station $\mathrm{C} 2$ for the spring tide, the observed pattern was similar to that at station $\mathrm{C} 1$ within a range of $80-350 \mathrm{mg} / \mathrm{L}$ and the numerical model calculated the variation pattern within a range of $150-500 \mathrm{mg} / \mathrm{L}$. In the above results, the concentration at low water could be not observed because the water depth was very shallow. Therefore, the observed and calculated concentrations at low water showed some discrepancy. For the neap tide, the observed concentrations at stations $\mathrm{C} 1$ and $\mathrm{C} 2$ varied within a narrow range of $30-70 \mathrm{mg} / \mathrm{L}$. Although the numerical solution did not show sensitive concentration variation, the computed concentration approximately coincided with the average observed concentration.

From the above verifications, the yearly deposition and erosion rates considering the seasonal flow discharge and sediment load from the stream were predicted, as shown in Fig. 7. An erosion rate of less than $-10 \mathrm{~cm} /$ year occurred in the main water channel and surrounding islands, where the flow was very strong. Conversely, weak deposition within a range of +0.5 to $5 \mathrm{~cm} /$ year occurred in the tidal flats around waterways. Heavy deposition of over $+10 \mathrm{~cm} /$ year was predicted in the upstream area of the estuary due to the continuously discharged sediment load from the stream. The predictions also showed that little erosion or deposition occurred on the tidal flats near the shoreline, likely because this area is only briefly in contact with water. On the basis of field observations, Choi (2004) reported that deposition of +1 to $6 \mathrm{~cm} /$ year occurred on tidal flats in this area. Therefore, the present model is considered to predict the bathymetric change reasonably well.

\section{Discussion}

\section{Tidal Flow Change by Structures}

In the Beolgyo Stream Estuary, a large bridge 


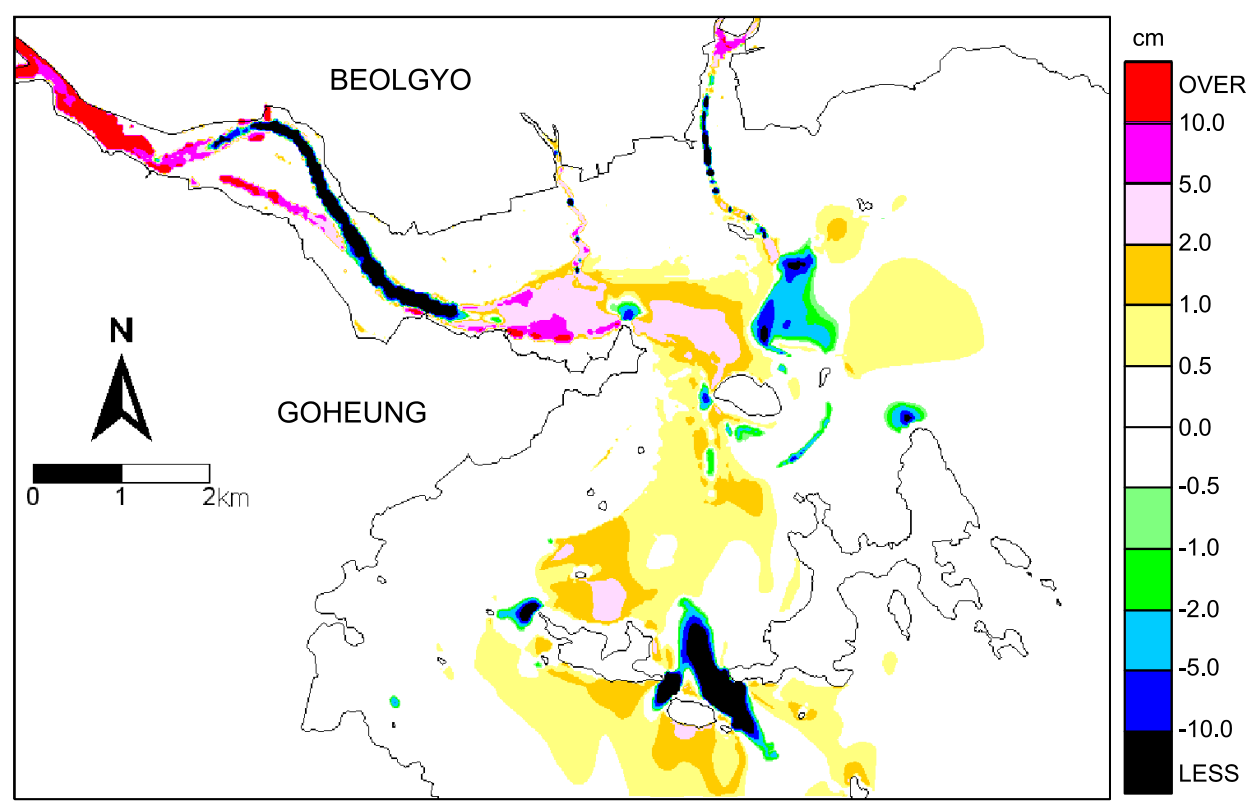

Fig. 7. Predicted erosion and deposition rate per year in Beolgyo Stream Estuary.

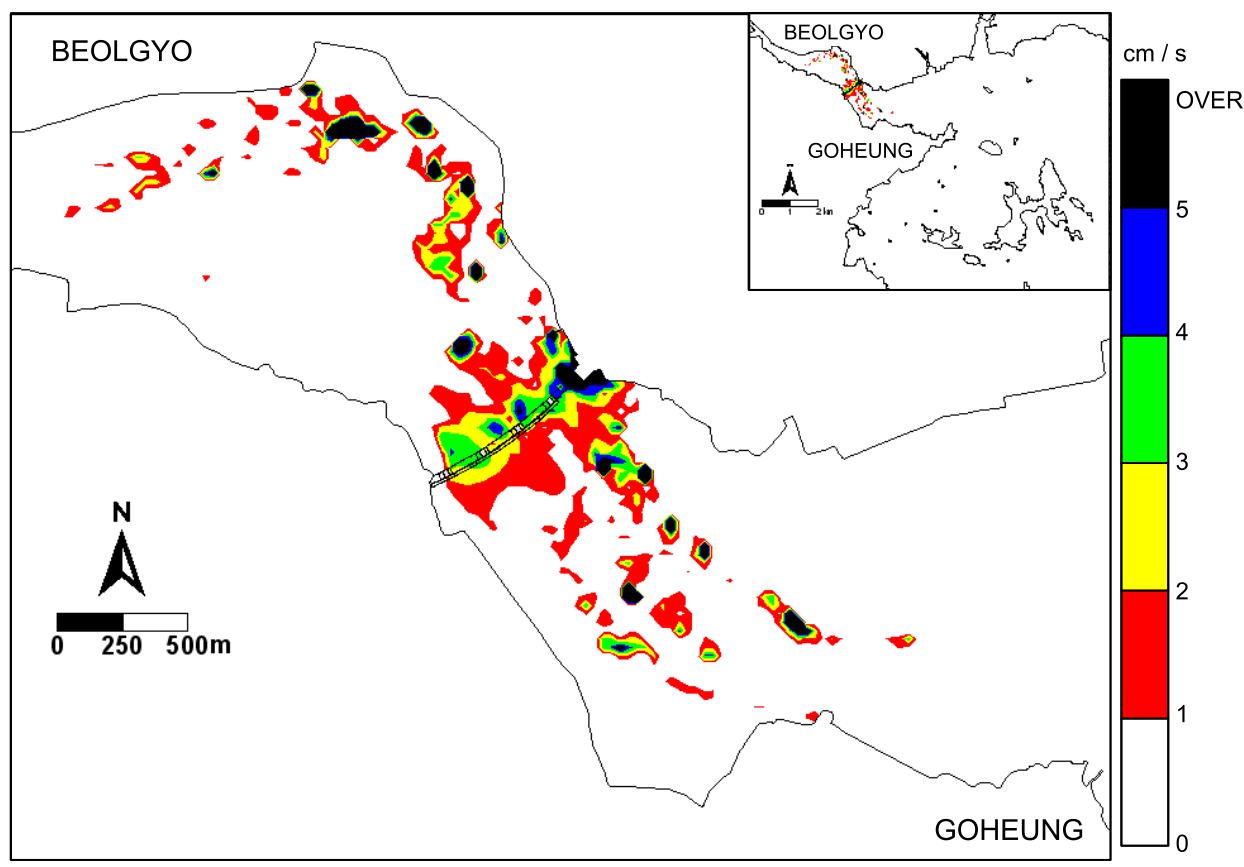

Fig. 8. Predicted tidal flow changes by the bridge construction for a spring tide.

between Beolgyo Town and Goheung County is under construction. The bridge is $940 \mathrm{~m}$ long and includes six piers and two abutments. In particular, the bridge piers are submerged in the water, leading to flow resistance which creates sudden flow variations such as eddies. Simulating flow resistance is a challenging problem. One reason is that it is difficult to represent submerged structures as dry cells, because the size of a pier's cross section is typically one to two orders smaller than the size of the computational grid. Furthermore, even if the structures are represented as dry cells using a very fine grid, it is difficult to estimate the eddy viscosity around the structures (Park et al., 1998). 
To resolve these problems, drag force considering the shape of the resistance body was introduced, as presented in Eq. (4). The drag coefficient of the piers was estimated to range from 1.79-2.05 and the pier shape was taken as a rectangular cylinder (Akins et al., 1977; Blevins, 1984; Park et al., 2009). The eddy viscosity in the turbulence diffusion term is important for flow reproduction around structures. Assuming a logarithmic velocity distribution, Elder (1959) proposed the eddy viscosity as follows:

$$
\varepsilon=k_{\varepsilon} U_{*} H
$$

Where $k_{\varepsilon}=$ constant and $U_{*}=$ shear velocity. Based on field data for coastal waters and estuaries, $k_{\varepsilon}$ is known to range from 0.42-1.61 in natural flows (Fischer, 1973). Falconer (1976) recommended a value of 1.2 in his numerical model. However, if wakes caused by artificial structures exist, it becomes difficult to determine the eddy viscosity coefficient. Hence, Eq. (11), using Prandtl's assumption (Reichardt, 1951; Görtler, 1942), is introduced in this study:

$$
\varepsilon=0.0222 C_{D} D U
$$

where $C_{D}=$ drag coefficient, $D=$ representative length such as the diameter of the structure, and $U=$ free stream velocity. To reformulate Eq. (11) in the same form as Eq. (10), $U$ is expressed as Eq. (12a), which is identical to Chezy's average velocity. In addition, $U_{*}$ is introduced as Eq. (12b) with the assumptions of a mild bottom slope and uniform flow:

$$
\begin{aligned}
& U=C \sqrt{R I} \\
& U_{*}=\sqrt{g R I}
\end{aligned}
$$

where $R=$ hydraulic radius, $I=$ bottom slope, and $C=$ Chezy coefficient. As shown in Eq. (13), $k_{\varepsilon}$ is derived by inserting Eq. (12) into Eq. (10) and Eq. (11):

$$
k_{\varepsilon}=\frac{0.0222 C_{D} D C}{\sqrt{g} H}
$$

In the case of the Beolgyo Bridge, because $C_{D}=1.79$ $2.05, D=25-30 \mathrm{~m}$, and $C=41-43$ by Bazin's Law, $k_{\varepsilon}$ is calculated to fall within a range of 4.34-6.25. This is about four to six times larger than that of natural flows, as given by Fischer (1973). However, it does coincide approximately with the results of Rodi (1972), who noted that the eddy viscosity coefficient of wakes is 3-13 times larger than that of pipes or jet flows.

Using the above formulation, the flow change before and after construction of the bridge was simulated with normal stream discharge for spring tide conditions (25 hours). As shown in Fig. 8, the velocity variation was particularly prominent around the piers in the tidal channel. The area with a flow speed change over $\pm 1 \mathrm{~cm} / \mathrm{s}$ was calculated to be 105.8 ha and the influence distance was measured to be approximately $1.8 \mathrm{~km}$ in the northwest direction from the bridge and about $1.7 \mathrm{~km}$ in the southeast direction.

\section{Bottom Topography Change by Structures}

Surface sediment samples from 15 stations around the bridge (Fig. 1) were collected and analyzed to obtain various geologic characteristics for estimating the settling velocity and critical shear stresses for deposition and erosion. Most of the stations had hard cohesive sediments with a mean diameter of $8.23 \varnothing$, an average mud content of $93.0 \%$, an average sand content of $7.0 \%$, an average organic content of $5.3 \%$, and an average dry density of $703.2 \mathrm{~kg} / \mathrm{m}^{3}$. This information is important in determining critical shear stresses for erosion and deposition.

The deposition rate depends on the settling velocity and critical shear stress for deposition in Eq. (8a). The settling velocity can be easily calculated using Stoke's Law (Eq. (9a)) when the suspended sediment concentration is below $10 \mathrm{mg} / \mathrm{L}$. However, if the suspended sediment concentration exceeds $10 \mathrm{mg} / \mathrm{L}$ (up to $10,000 \mathrm{mg} / \mathrm{L}$ ), the settling velocity can also be calculated using Eq. (9b). To use these equations in the numerical models, proper values for the constant $k$ and the exponent index of concentration $m$ must be determined. In the Beolgyo Stream Estuary, when the suspended sediment concentration is just $10 \mathrm{mg} / \mathrm{L}, k$ can be calculated to be 0.884 with an average grain size of $8.23 \varnothing$ by matching Eq. (9b) with Eq. (9a). Also, as shown in Fig. 9, $m$ likely ranges between 0.5 and 1.5 based on the correlation between the settling velocity and sediment concentration proposed by van Rijn (1993). The $m$ value was verified with test simulations, as shown in Fig. 10(a), where the computed con-centrations were compared with observations at station $\mathrm{C} 1$ for a spring tide. When $m=0.5$, the computed concentration was overestimated in relation to the observed data due to small settling velocity. In contrast, when $m=1.5$, the computed con-centration was underestimated as a result of high settling velocity. As expected, when $m=1$, the com-puted and observed values coincided well. Mean-while, according to the findings of Winterwerp et al. (1991), the critical shear stress for deposition $\tau_{d}$ was estimated from the observed geologic characteristics 


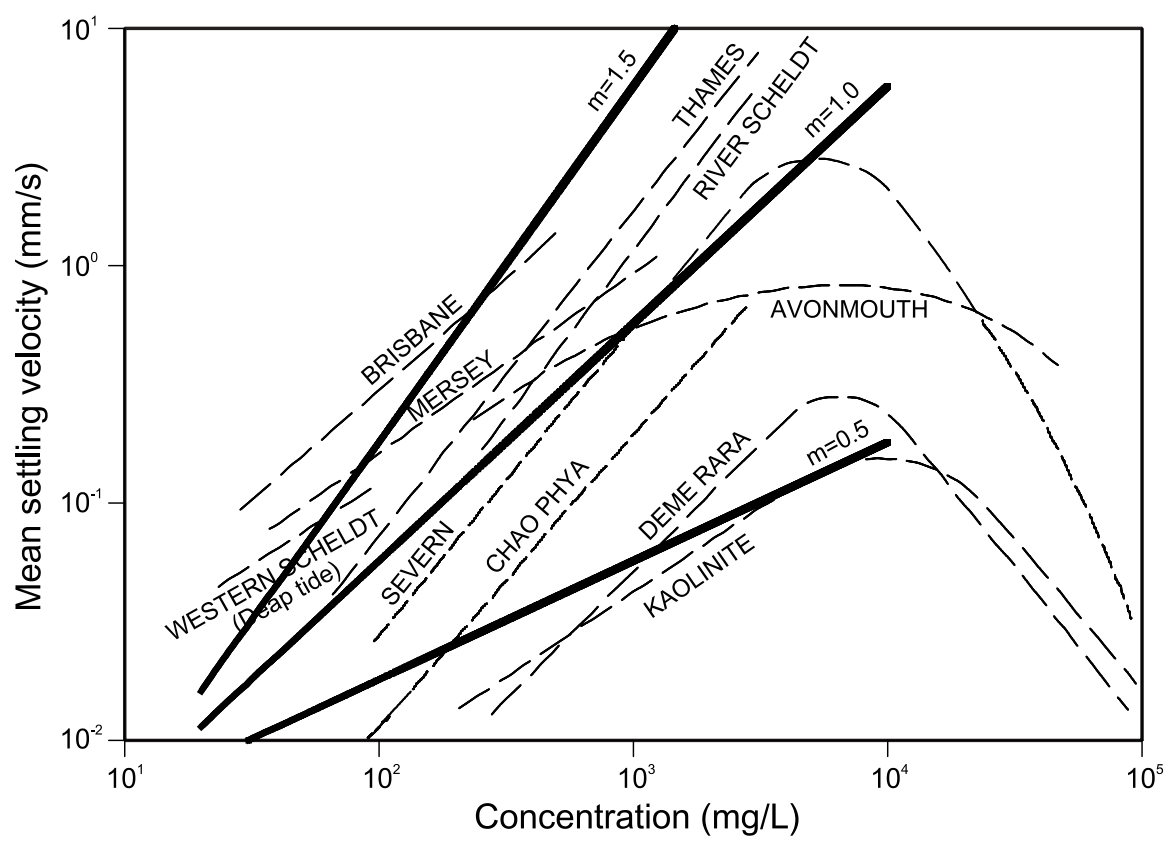

Fig. 9. The influence of sediment concentration on the settling velocity (see van Rijn, 1993), where the colored lines are the proposed settling velocity according to $m$ with $k=0.884$ at $S=10 \mathrm{mg} / \mathrm{L}$.

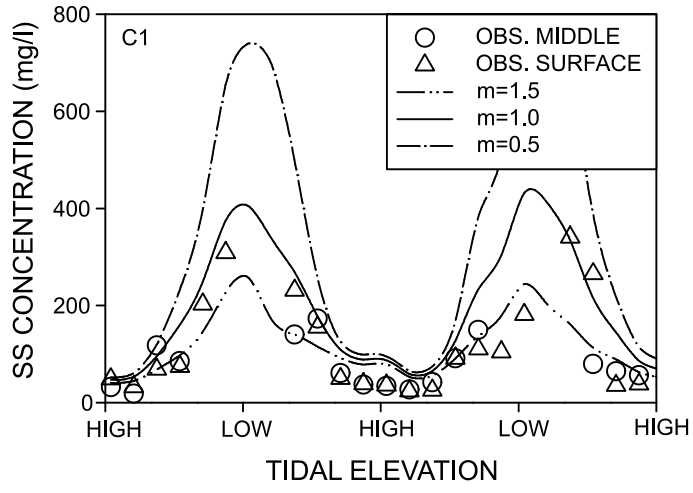

(a) Exponent index of concentration $m$

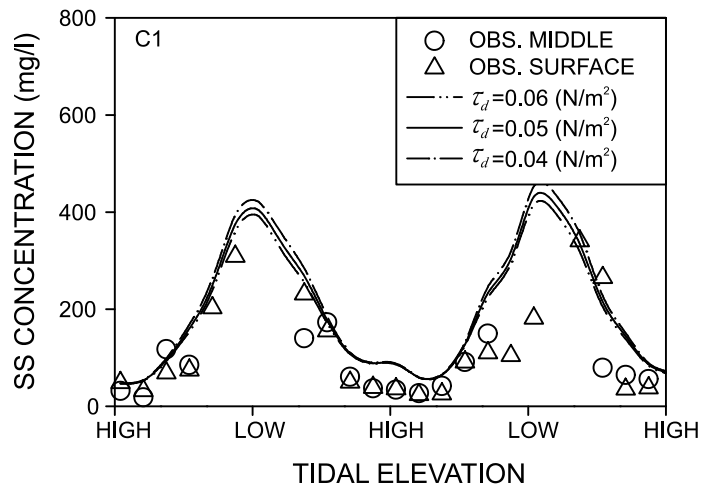

(b) Critical shear stress for deposition $\tau_{d}$

Fig. 10. Variation of suspended sediment concentrations according to $m$ and $\tau_{d}$.

to fall within a range of $0.04-0.06 \mathrm{~N} / \mathrm{m}^{2}$. The computed concentration according to $\tau_{d}$ was not significantly changed as seen in Fig. 10(b). Therefore, the median value of $0.05 \mathrm{~N} / \mathrm{m}^{2}$ can be considered a suitable value for the critical shear stress for deposition in the area of interest.

The erosion rate is influenced by the proportional constant, $M$, and the critical shear stress for erosion, $\tau_{e}$, as delineated in Eq. (8b). By comparing the observed geologic characteristics with the values reported by Winterwerp et al. (1991), $\tau_{e}$ can be estimated to fall within a range of $0.8-1.2 \mathrm{~N} / \mathrm{m}^{2}$. As shown in Fig. 11(a), the computed concentration was inversely proportional to $\tau_{e}$ and the observed and computed values appear to coincide well when $\tau_{e}=$ $1.0 \mathrm{~N} / \mathrm{m}^{2}$. In general, $M$ is known to be range from 0.00001-0.0005 in natural mud (van Rijn, 1993). Using the trial and error method, $M$ was estimated to lie within a range of 0.0001-0.0003. As shown in Fig. 11(b), the computed concentration was underestimated compared to the observed value when $M=$ 0.0001 and overestimated when $M=0.0003$. Therefore, the optimal value may be $M=0.0002$.

Through the above verifications, the empirical constants were found to be $k=0.884, m=1.0, \tau_{d}=$ $0.05 \mathrm{~N} / \mathrm{m}^{2}, \tau_{e}=1.0 \mathrm{~N} / \mathrm{m}^{2}$, and $M=0.0002$. Using these verified constants, the computed concentrations were represented by all observed stations and tidal phases, 


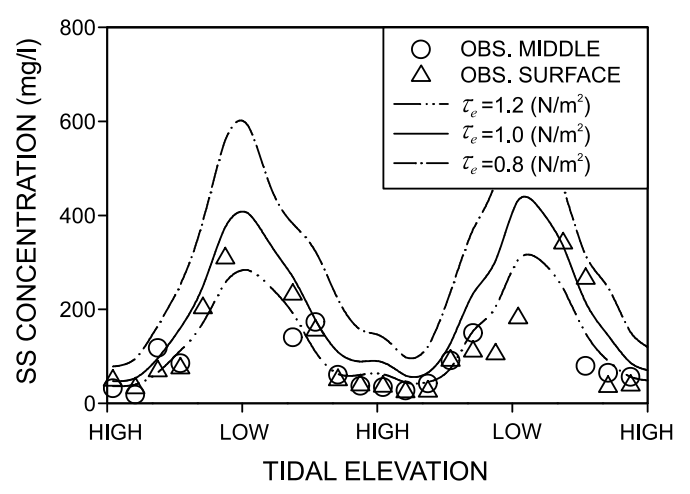

(a) Critical bed-shear stress for erosion $\tau_{e}$

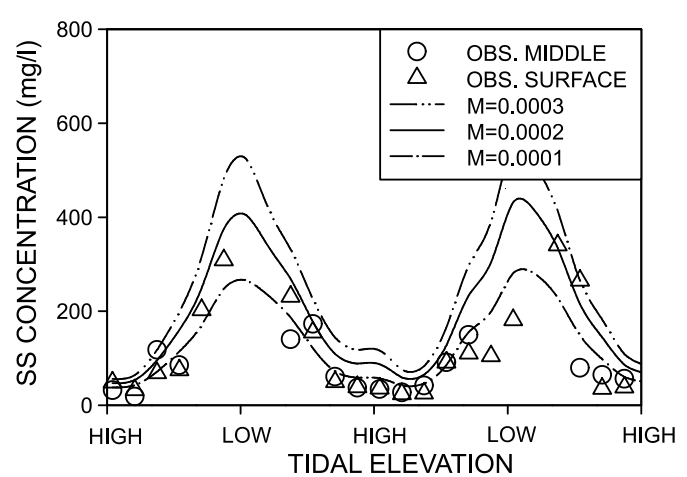

(b) Coefficient $M$

Fig. 11. Variation of suspended sediment concentrations according to $\tau_{e}$ and $M$.

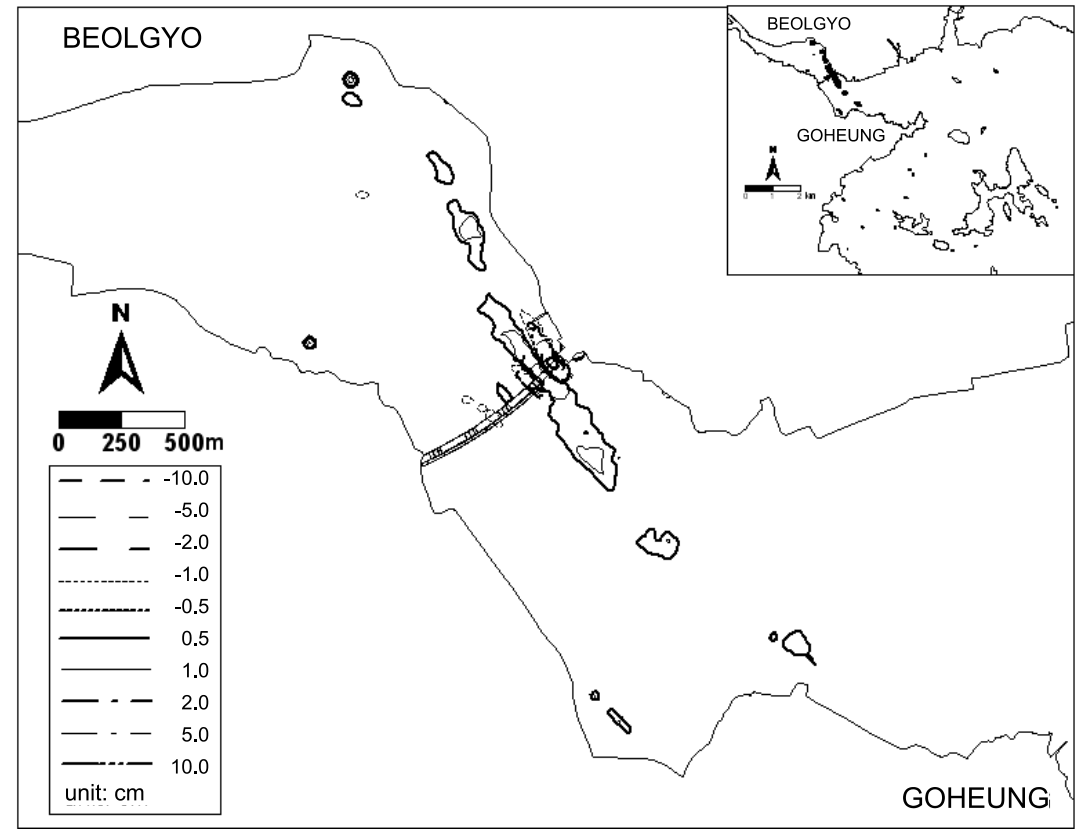

Fig. 12. Predicted yearly bathymetric changes before and after the bridge construction in Beolgyo Stream Estuary.

as illustrated in Fig. 6. The variation pattern of the computed concentrations was well explained with the observed data at stations $\mathrm{C} 1$ and $\mathrm{C} 2$ for the spring and neap tides, respectively. Therefore, the verified constants were used to compute the bathymetrical changes related to cohesive sediment transport. Fig. 12 presents change in erosion and deposition rates before and after the bridge construction. The results indicate that erosion will occur mainly along the tidal channels near the piers due to strong flow resulting from the reduced flow cross section created by bridge structures. In contrast, at the rear area of the structure where flow is relatively weak due to eddy formation, deposition and moderated erosion were predicted.

In estuaries and coastal waters, changes in the flow environment caused by bridge piers and other artificial structures can produce changes in the sedimentary environment, and this change of the physical environment can affect local marine ecosystems. The numerical model proposed in this study will enable systematic predictions of changes to flow and sedimentary environments caused by the construction of artificial structures. The results of this study can also serve as baseline data for determining the effects of artificial structures on marine ecosystems. 


\section{References}

Akins RE, Peterka JA and Cermak JE. 1977. Mean force and momentum coefficients for buildings in turbulent boundary layers. J Indust Aeronaut 2, 195-209.

Blevins RD. 1984. Applied fluid dynamics handbook. In Chapter 10, Van Nostrand Reinhold Company, 279-311.

Choi JM. 2004. Sediment behavior mechanism in Yeoja Bay, south coast of Korea. Doctoral Thesis, Oceanography Program, Department of Fisheries Science, Yeosu National University.

Elder JW. 1959. The dispersion of market fluid in turbulence shear flow. J Fluid Mechanic 5, 544-560.

Falconer RA. 1976. Mathematical modelling of jet-forced circulation in reservoirs and harbours. Thesis submitted to University of London in partial fulfillment of degree of Ph.D., November.

Falconer RA. 1986. A two-dimensional mathematical model study of the nitrate levels in an inland natural basin. Proceedings of the International Conference on Water Quality Modelling in the Inland Natural Environment, BHRA Fluid Engineering, Bournemouth, England, Paper J1, June, 325-344.

Falconer RA. 1991. Review of modelling flow and pollutant transport processes in hydraulic basins. In Proceeding 1st International Conference on Water Pollution: Modelling, Measuring and Prediction, Southampton, Computational Mechanics Publications, September, 3-23.

Falconer RA and Owens PH. 1987. Numerical simulation of flooding and drying in a depth-averaged tidal flow model. In Proceeding Institution of Civil Engineering, 83, Part 2, March, 161-180.

Fischer HB. 1973. Longitudinal dispersion and turbulent mixing in open channel flow. Annual Review of Fluid Mechanics, 5, 59-78.

Gailani J, Ziegler CK, and Lick W. 1991. Transport of suspended solids in the Lower Fox Fiver. J Great Lakes Research 17, 479-494.

Görtler H. 1942. Berechnung von aufgaben der freien turbulenz auf grundeines neuen näherungsa-ansatzes. ZAMM 22, 244-245.

Huber WC and Dickinson RE. 1988. Storm water management model, version 4: User's manual version 2.1, U.S. Army Corps of Engineers, Computer Program 723-S8-L7520.

Jung TS, Kim TS and Jeong DK. 2006. Numerical modeling of cohesive sediment transpot at Mokpo coastal zone. J Korean Soc Marine Environ Eng 9, 3644.

Krone RB. 1963. A study of rheologic properties of estuarial sediments. SERL Report No. 63-8, Hy-draulic Engineering Laboratory and Sanitary Enginee-ring
Research Laboratory, University of California, Berkeley. Lee JS and Park IH. 1995. Evaluation and numerical model of hydraulic resistance by hanging aquaculture facilities. J Korean Fish Soc 28, 607-623.

Mehta AJ and Partheniades E. 1973. Effect of physicochemical properties of fine suspended sediment on the fegree of deposition. In Proceeding of International Symposium on River Mechanics, IAHE, 1, Bangkok, Tailand, January.

Mehta AJ and Parchure TM. 1982. Resuspension potential of deposited cohesive sediment beds, in estuarine comparison, V.S. Kennedy(ed), Academy Press, New York.

Mehta AJ, Mcanally WH, Hayter EJ, Teeter AM, Schoellhamer D, Helzel SB, and Carey WP. 1989. Cohesive sediment transport II: application. J Hydraulic Eng 115, 1094-1112.

Oey LY. 2006. An OGCM with movable land-sea boundaries. Ocean Modelling 13, 176-195.

Owen MW. 1976. Determination of the settling velocities of cohesive muds. No. INT 161, Hydraulics Research Station Report, Wallingford, United Kingdom.

Parchure TM. 1984. Erosional behavior of deposited cohesive sediment. Ph.D. Dissertation, University of Florida, Gainesvill, Florida.

Park IH. 2004. Evaluation of tidal flow around the pilesupported pier structures. J Korean Soc Marine Environ Eng 7, 82-88.

Park IH, Lee GH and Cho YJ. 2009. Drag coefficient estimation of pile type structures by numerical water basin experiments. J Korean Soc Coastal Ocean Eng 21, 45-53.

Park IH, Lee JS, and Lee MO. 1998. A numerical model of large scale grid for two-dimensional wake behind bodies. J Korean Soc Coastal Ocean Eng 10, 83-82.

Partheniades E. 1965. Erosion and deposition of cohesive soils. J Hydraulic Division ASCE 91, No. HY1, 105138.

Partheniades E. 1977. Unified view of wash load and bed material load. J Hydraulic Division ASCE 103, No. HY9, 1037-1057.

Reichardt H. 1951. Gesetzmässigkeiten der freien turbulenz. VDI-Forschung-sheft 414(1942), 2nd Edtion.

Rodi W. 1972. The prediction of free turbulent boundary layers by use of two-equation model of turbulence. Ph.D. Thesis, University of London.

Shrestha PL, and Orlob G. 1996. Multiphase distribution of cohesive sediments and heavy metals in estuarine systems. J Environ Eng 122, 730-740.

Shrestha PL, Blumberg AF, Di Toro DM and Hellweger FL. 2000. A three-dimensional model for cohesive sediment transport in shallow bays. Minneapolis: ASCE Proceedings, Joint Conference on Water Resources 
Engineering and Water Resources Planning and Management.

Teeter AM and Pankow W. 1989. The Atchafalaya River Delta: field data: settling characteristics of bay sediments. Technical Report 2, HL-82-15, Waterways Experiment Station, United States Army Engineers, Vicksburg, Mississippi.

van Rijn LC. 1984. Sediment transport part 1: suspended load transport. J Hydraulic Eng 110, 1613-1641.

van Rijn LC. 1993. Principles of sediment transport in rivers, estuaries and coastal seas. Amsterdam, Aqua
Publications.

Winterwerp JC, Cornelisse JM and Kuijper C. 1991. Erosion of natural sediments from the Netherlands. Report Z161-35/37, Delft Hydraulics, Delft, The Netherlands.

Ziegler CK and Nisbet B. 1994. Fine-grained sediment transport in Pawtuxet River Rhode Island. J Hydraulic Eng 120, 561-576.

(Received 21 April 2010; Revised 17 May 2010; Accepted 10 June 2010) 